\title{
EXPERIÊNCIAS INTERCULTURAIS NA UNIVERSIDADE: A PRESENÇA DOS INDÍGENAS EAS CONTRIBUIÇÕES À LEI N 11.645/08
}

\author{
Adir Casaro Nascimento ${ }^{1}$ (D) \\ Carlos Magno Naglis Vieira ${ }^{1}$ (D) \\ Beatriz dos Santos Landa ${ }^{2}$ (D)
}

\begin{abstract}
RESUMO: Na expectativa de sensibilizar a nossa percepção do ver e de nos permitir ser afetados pelas relaçóes epistêmicas outras produzidas, o artigo tem como objetivos apresentar e refletir sobre as contribuições que a presença dos acadêmicos indígenas trazem para as disciplinas que são amparadas ou atravessadas pelos conteúdos da Lei $\mathrm{n}^{\circ} 11.645 / 08$ e que têm possibilitado a experiência de descentramento do pensamento hegemônico que domina a academia. Depoimentos de indígenas e náo indígenas evidenciam as fissuras, as produçôes e as reelaborações que têm sido produzidas nesses espaços de tensão acadêmica.
\end{abstract}

Palavras-chave: Experiências decoloniais. Interculturalidade. Lei ${ }^{\circ}$ 11.645/08. Acadêmicos indígenas. Mato Grosso do Sul.

\section{Intercultural experiences in the university: the presence of indigenous people and contributions to Law No. 11.645/08}

ABSTRACT: In the expectation of sensitizing our perception of seeing and allowing ourselves to be affected by these "other"

\footnotetext{
${ }^{1}$ Universidade Católica Dom Bosco - Mato Grosso do Sul (MS), Brasil.

E-mails: adir@ucdb.br; cmhist@hotmail.com

${ }^{2}$ Universidade Estadual do Mato Grosso do Sul - Mato Grosso do Sul (MS), Brasil.

E-mail: bialanda@uol.com.br
}

DOI: $10.1590 / C C 0101-32622019216671$ 
epistemic relationships produced, the article aims to present and reflect the contributions that the presence of indigenous academics brings to the disciplines that are supported or crossed by the contents of Law 11.645/08 and that has enabled the experience of decentralization of hegemonic thinking that dominates the academy. Testimonies of indigenous and non-indigenous people highlight the fissures, productions and re-elaborations that have been produced in these areas of academic tension.

Keywords: Decolonial experiments. Interculturality. Law No. 11.645/08. Indigenous academics. Mato Grosso do Sul.

\section{INTRODUÇÃO}

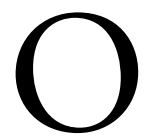

estado do Mato Grosso do Sul apresenta uma população indígena de aproximadamente 77 mil pessoas (IBGE, 2010), o segundo em número populacional do país, distribuídos em 8 povos. Há uma presença significativa de acadêmicos indígenas nos espaços das universidades, cursando graduação e pós-graduação. Matriculados em instituições públicas e privadas, nas modalidades presencial e a distância, os acadêmicos estáo inscritos em diferentes cursos de graduaçáo como, Pedagogia, Letras (Português/Espanhol e Inglês), História, Ciências Sociais, Ciências Biológicas, Educação Física, Direito, Enfermagem, Nutrição, Fisioterapia, Química, Agronomia, Engenharia de Alimentos, entre outros. Na pós-graduaçáo, registramos a presença de mestrandos e doutorandos indígenas em diversos programas, tanto no Mato Grosso do Sul quanto em outros estados.

Partindo das experiências dos autores, ou seja, dos eventos vividos que aconteceram, nos marcaram e tocaram (LARROSA, 2002), nos cursos de graduação em licenciatura de duas instituiçôes de ensino superior do Mato Grosso do Sul, Universidade Católica Dom Bosco (UCDB) e Universidade Estadual de Mato Grosso do Sul (UEMS), ,e no Programa de Pós-Graduação em Educação da UCDB, é possível observar que os acadêmicos indígenas, ao longo do tempo, vêm provocando tensão 
e instabilidade nas disciplinas e nas relaçóes, principalmente no pensar outras lógicas epistemológicas, metodológicas e culturais. Eles suscitam desconforto/desestabilização na maneira de perceber o outro e em determinadas práticas pedagógicas (NASCIMENTO, 2014; CANDAU, 2016; WALSH, 2009; 2016) e, nesse sentido, afetam acadêmicos indígenas e não indígenas no que diz respeito ao processo de formação para a prática da Lei $n^{\circ}$ 11.645/08, foco deste artigo.

Nossas vivências com acadêmicos indígenas têm nos anunciado a possibilidade da quebra dos estereótipos e preconceitos rigidamente produzidos pelos contextos coloniais, principalmente na escola, ao fixar conceitos hierarquizados, totalitários e de uma universalização excludente dos saberes outros, nestse caso, o dos indígenas. A expectativa é que tal convivência venha produzindo tensóes e deslocamento na formação de professores/educadores não só enquanto titulares das disciplinas compromissadas diretamente com a Lei $\mathrm{n}^{\circ} \mathrm{o} 11.645 / 08$, mas que possa transversalizar e estar produzindo novas identidades interculturais, conteúdos e pedagogias decoloniais.

$\mathrm{Na}$ expectativa de sensibilizar a nossa percepção do ver e de nos permitir ser afetados por essas verdades outras produzidas, o artigo tem como objetivo apresentar e refletir sobre as contribuiçóes que a presença dos acadêmicos indígenas, matriculados nos cursos de licenciaturas e na pós-graduação, trazem para as disciplinas e as relações que são amparadas ou atravessadas pelos conteúdos da Lei $n^{\circ}$ o $11.645 / 08$. Nesse sentido, partimos do princípio de que os estudos que fazemos nos currículos desses cursos, além de apresentar assuntos referentes à temática da cultura indígena e afro-brasileira, procuram trazer inquietaçóes, problematizações, desconstruçóes e questionar as "formas totalizantes e absolutizantes do pensamento hegemônico na modernidade [...] [seria como] uma experiência de descentramento, de se sair das próprias certezas e verdades construídas a partir do pensamento hegemônico" (AZIBEIRO; FLEURI, 2010, p. 286).

Sensibilizados, borrados e marcados pelo pensamento de autores e dos indígenas que transitam nesses espaços, que a todo o momento nos direcionam a uma vigilância epistemológica do desaprender, do desconstruir e do ressignificar a modernidade racional, entendemos que nos ambientes universitários em que os cursos possuam disciplinas que contemplem conteúdos da Lei $n^{\circ}$ o $11.645 / 08$, e que tenham a presença de indígenas, possam ser espaços interculturais com a possibilidade de expe- 
riências de Pedagogias Decoloniais, em que as práticas de escutar o outro, e construir formas outras de ser e pensar, sejam centrais e promovam deslocamentos epistêmicos (WALSH, 2009; 2016; CANDAU, 2016; NASCIMENTO, 2014; QUIJANO, 2005; LARROSA, 2002).

Com base nos estudos de Catherine Walsh (2009, p. 25), os espaços interculturais seriam:

Como ferramenta pedagógica que questiona continuamente a racialização, subalternizaçáo, inferiorizaçáo e seus padrôes de poder, viabiliza maneiras diferentes de ser, viver e saber e busca o desenvolvimento e criaçáo de compreensões e condiçóes que não só articulam e fazem dialogar as diferenças num marco de legitimidade, dignidade, igualdade, equidade e respeito, mas que - ao mesmo tempo - aceitam a criação de modos "outros" - de pensar, ser, estar, aprender, ensinar, sonhar e viver que cruzam fronteiras.

Assim, dez anos após a promulgação da Lei $n^{\circ}$ o $11.645 / 08$, além de utilizar as experiências vividas pelos autores em sala de aula das universidades, por meio de entrevistas com acadêmicos indígenas e não indígenas, o texto busca verificar as contribuiçóes, identificar as fissuras, as produçóes e as reelaboraçóes que estes alunos trazem para as disciplinas e para aqueles com quem convivem, escutam e se relacionam (NASCIMENTO, 2014; WALSH, 2009; 2016).

\section{SITUANDO A LEI N ${ }^{\circ 0}$ 11.645/08 E AS UNIVERSIDADES ONDE AS EXPERIÊNCIAS DOCENTES E ACADÊMICAS OCORREM}

A Lei ${ }^{\circ}$ o $11.645 / 08$, que alterou a Lei $n^{\circ} 10.639 / 03$ ao incluir no currículo oficial da rede de ensino a temática história e cultura afro-brasileira e indígena, surgiu de intensos debates e inúmeras lutas e tensōes dos movimentos afrodescendentes e indígenas. Por esse motivo, concordamos com o estudo de Russo e Paladino (2016) que apresenta a discussão sobre a Lei $\mathrm{n}^{\circ} \mathrm{o} 11.645 / 08$ bem antes da sua implementação em 2008. 
Segundo as autoras, as reflexóes da Lei iniciaram-se com a Constituição de 1988, com as legislaçóes brasileiras que se referem às populaçôes indígenas (Lei de Diretrizes e Bases de 1996; Parecer do Conselho Nacional de Educação no 14 e Resolução da Câmara de Educação Básica CEB no 3, de 1999; Lei ${ }^{\circ}$ o 10.172, de 9 de janeiro de 2001, que institui o Plano Nacional de Educaçáo, entre outros), os Parâmetros Curriculares Nacionais $(\mathrm{PCN})$.

Com o aumento do preconceito, da discriminação, da subalternização, da inferiorização, da denúncia e das tensóes envolvendo as populaçóes indígenas, o governo federal amplia a Lei $\mathrm{n}^{\circ}$ o 10.639/03 e institui a obrigatoriedade da temática história e cultura afro-brasileira e indígena no currículo escolar da educação básica, conforme a seguir, homologando a Lei $\mathrm{n}^{\circ}$ o 11.645/08 que, em seu artigo 26-A, rege: "Nos estabelecimentos de ensino fundamental e de ensino médio, públicos e privados, torna-se obrigatório o estudo da história e cultura afro-brasileira e indígena” (BRASIL, 2008).

Em uma primeira leitura na redação do artigo citado anteriormente e com base em algumas manifestaçóes de acadêmicos não indígenas, observamos que seu conteúdo pode ter interpretaçôes que delimitam a obrigatoriedade do estudo da história e cultura afro-brasileira e indígena somente para as escolas de ensino fundamental e médio. Porém, a implementação da Lei só será possível se for compreendida em seu sentido amplo, ou seja, ter lugar significativo nos currículos de formação de professores e pesquisadores das temáticas envolvidas.

Para os acadêmicos indígenas de nossas instituiçóes, a presença de uma disciplina nos cursos que contemple assuntos referentes aos povos indígenas já traz tensionamento, desconforto e desconstrução da cultura do silêncio (SACAVINO, 2016). Com base no que diz a autora, fazer emergir a cultura do silêncio, significa trazer para a discussão outras histórias ou histórias outras, o que resulta na valorização e na produção de histórias de povos que foram inferiorizados, colonizados e ainda estão vivendo na fronteira da exclusão.

Nesse sentido, talvez seja interessante registrar que as duas instituiçóes, por conta da grande presença indígena no estado do Mato Grosso do Sul, sempre tiveram acadêmicos indígenas em seus ambientes. 
Embora a chegada ao ensino superior tenha sido motivada por interesses coletivos (reivindicaçóes dos movimentos, das organizaçóes indígenas, das comunidades) e, também, por iniciativas individuais e/ou das famílias, o acolhimento, por parte das instituiçóes, na maioria das vezes propiciou o alcance do conhecimento eurocêntrico com base epistemológica moderna, sem percepção da possibilidade de abrir um diálogo intercultural. Em nossas observaçóes, os indígenas não eram invisíveis, mas não tinham espaços para legitimar os seus conhecimentos, histórias, cosmovisóes e epistemologias. No máximo, na maioria das vezes, eram vistos com tolerância (SKLIAR, 2003).

Com o advento da Lei ${ }^{\circ}$ o $11.645 / 08$ e com a obrigatoriedade de pluralidade, diversidade e diferenças nos currículos do ensino superior e na educação básica, coordenadores, professores e pesquisadores dos cursos de graduação e do stricto sensu, com o objetivo de cumprir as determinações legais, começam a perceber uma presença outra dos indígenas nos espaços acadêmicos.

Assim sendo, ao observar o desdobramento do artigo 26 da lei:

$\$ 1$ o O conteúdo programático a que se refere este artigo incluirá diversos aspectos da história e da cultura que caracterizam a formação da população brasileira, a partir desses dois grupos étnicos, tais como o estudo da história da África e dos africanos, a luta dos negros e dos povos indígenas no Brasil, a cultura negra e indígena brasileira e o negro e o índio na formação da sociedade nacional, resgatando as suas contribuiçóes nas áreas social, econômica e política, pertinentes à história do Brasil.

$\$ 2$ o Os conteúdos referentes à história e cultura afro-brasileira e dos povos indígenas brasileiros serão ministrados no âmbito de todo o currículo escolar, em especial nas áreas de educação artística e de literatura e história brasileiras (BRASIL, 2008).

Professores e alunos começam a dar uma outra visibilidade aos indígenas em sala de aula, embora a colonialidade ainda tenha uma forte 
presença ambivalente entre a contribuição que os indígenas podem trazer e a tendência de folclorizaçáo e exotismos de suas participaçóes.

Por outro lado, acadêmicos náo indígenas são surpreendidos com temas nunca discutidos em sala de aula, como território, territorialidade, indígenas urbanos, natureza como cosmovisão, conhecimento não fragmentado, contradisciplinaridade e epistemologias outras.

Ao realizar uma leitura mais atenta dos parágrafos da Lei $\mathrm{n}^{\circ} \mathrm{o} 11.645 / 08$, observamos que além de apresentar os possíveis conteúdos que podem ser trabalhados nas práticas pedagógicas dos professores, a Lei não é responsabilidade de algumas áreas do conhecimento (história, literatura e educação artística), mas deve estar presente ou atravessada em todas as disciplinas do currículo escolar.

Por esses motivos apresentados, optamos por trazer para a discussão os espaços acadêmicos onde as nossas experiências interculturais enquanto docentes são realizadas com os indígenas e não indígenas (acadêmicos, mestrandos e doutorandos). As universidades mencionadas, além de assumirem o compromisso com a Lei $\mathrm{n}^{\circ} \mathrm{o} 11.645 / 08$ na formação de futuros professores, criam espaços para a circulação dos povos indígenas, provocam fissuras nas práticas pedagógicas e introduzem a possibilidade de um pensamento outro, um modo outro (WALSH, 2016).

Para que os espaços dessas universidades, enquanto lugares que provocam a interculturalidade, ou seja, que se abrem para outros conhecimentos, que não os legitimados pela modernidade como únicos e absolutos, possam ser compreendidos, faremos uma breve apresentação.

A UEMS, com sede na cidade de Dourados (MS), foi criada em 1979 e sua implantação ocorreu no ano de 1994. Priorizou a democratização do acesso à educação superior pública, interiorizando suas unidades universitárias em 15 municípios e, hoje, em mais 10 cidades na modalidade a distância com forte presença na educação superior do estado.

Em relação à questão indígena, a implantação do sistema de cotas ocorreu por meio da Lei Estadual no 2.589, de 26 de dezembro de 2002 e aprovada por meio da Resolução COUNI/UEMS n 241, de 17 de julho de 2003. Essa legislação representou uma grande mudança no perfil dos acadêmicos da instituição, pois além das cotas para 
indígenas (394 matriculados), também possui cotas de 20\% para negros em todos os seus cursos de graduação desde o ano de 2004. A partir dessa nova configuração estudantil, vários projetos foram sendo desenvolvidos para atender a esses dois públicos, mas, neste artigo, serão destacados somente dois pelo fato de os indígenas serem o público preferencial.

Desde o ano de 2005, o Projeto Rede de Saberes ${ }^{1}$ vem sendo executado e tem como objetivo apoiar a permanência de alunos indígenas em sua trajetória acadêmica por meio de açóes variadas como encontros, cursos, seminários etc. e também o fortalecimento da articulação entre os acadêmicos com suas comunidades e acompanhamento da sua inserção profissional. Outra ação importante foi a execução do projeto Equidade na Pós-Graduação: o acesso de populaçóes sub-representadas ${ }^{2}$, com o qual foram preparados indígenas e negros para programas stricto sensu. Inscreveram-se 300 pessoas que concorreram em seleçóes no Mato Grosso do Sul e fora dele.

Desde então, e atendendo às legislações que foram sendo criadas por meio das lutas dos movimentos indígenas, os cursos da UEMS foram adaptando-se e disciplinas que atendem direta ou indiretamente à Lei $\mathrm{n}^{\circ} \mathrm{o} 11.645 / 08$ foram criadas, especialmente nas licenciaturas, como por exemplo, Fundamentos e Metodologia da Educação Escolar Indígena no curso de Pedagogia, Literaturas Afro-Brasileiras e Textualidades Indígenas no curso de Letras-Espanhol, Direitos Humanos e as Relaçóes Étnico-Raciais e de Gênero no curso de Ciências Biológicas, que estão transformando as relaçóes no cotidiano escolar.

A UCDB está presente no Mato Grosso do Sul, mais precisamente em Campo Grande, capital do estado, desde o ano de $1961 \mathrm{com}$ a Faculdade Dom Aquino de Filosofia, Ciências e Letras. Criada em 1993, a UCDB é mantida pela Missão Salesiana de Mato Grosso e possui uma história missionária com os povos indígenas. Porém, nos últimos 20 anos, a UCDB por meio de projetos e programas, bolsas para graduaçáo, atividades de pesquisa e extensão tem desenvolvido uma consistente ação acadêmica para e com os povos indígenas. Esse compromisso evidenciase pela constituição de um núcleo de pesquisa denominado Núcleo de Estudos e Pesquisas das Populaçóes Indígenas (NEPPI/UCDB) ${ }^{3}$, pela organização de um periódico acadêmico voltado aos assuntos indígenas a Revista Tellus, pela presença de mais de 100 acadêmicos indígenas nos 
cursos de graduação com bolsas da universidade e pelo apoio do Projeto Programa Rede de Saberes. Além disso, criou-se a linha de pesquisa Diversidade Cultural e Educação Indígena no Programa de Pós-Graduação em Educação, realizaram-se seminários específicos para os povos indígenas ${ }^{4} \mathrm{e}$ começaram as disciplinas Cultura e História Indígena e Cultura e História Afro-Brasileira, ministradas nos cursos de formação de professores/licenciatura para contemplar a exigência da Lei $\mathrm{n}^{\circ} \mathrm{o} 11.645 / 08$.

Ministradas na universidade desde o ano de 2012, as disciplinas inseridas nos currículos dos cursos de licenciatura, foram pensadas e organizadas para atender a uma orientação e obrigatoriedade do Ministério da Educação e Cultura (MEC). Com isso, as disciplinas,, além de apresentar conteúdos referentes à temática da Lei, trazem inquietaçóes, problematizaçóes, questionamentos e procuram construir "um processo dinâmico sempre em processo de fazer-se e refazer-se dada a permanência e capacidade de reconfiguraçáo da colonialidade do poder" (WALSH, 2016, p. 72).

Pelas experiências dos autores e amparados nas reflexóes de Catherine Walsh (2016), as disciplinas Cultura e História Indígena, Cultura e História Afro-brasileira, Fundamentos e Metodologia da Educação Escolar Indígena, no curso de Pedagogia, e demais disciplinas ministradas no âmbito dos cursos de graduação e pós-graduação tensionam os acadêmicos a desconstruir verdades impostas pela colonização, ressignificar percepçóes e olhares com relação às questôes hegemônicas, fantasiosas e colonialistas, que envolvem não somente as populações indígenas e suas histórias, mas tentam despertar uma compreensão crítica, consciente do passado e presente, que se abre e levanta questóes, perspectivas e caminhos (WALSH, 2016). Seria como uma "abertura e liberdade de pensamento a outras formas de vida, (outras economias, teorias políticas, etc.), limpeza da colonialidade do ser e do saber, o afrouxamento da retórica da modernidade e seu imaginário imperial articulado na retórica da democracia” (MIGNOLO, 2007, p. 29-30).

\section{A PRESENÇA INDÍGENA NO ESPAÇO ACADÊMICO E AS CONTRIBUIÇÕES À LEI No 11.645/08}

Tratar da temática indígena no espaço da universidade é uma experiência marcada inicialmente por processos de estranhamento, des- 
confiança, curiosidade, desconforto e/ou desconstrução/reconstrução de ideias que formaram o imaginário de uma parte significativa da sociedade brasileira que tem os indígenas como inexistentes e/ou invisibilizados e quando vistos tratados como inferiores/marginalizados. Essa situação também se dá por parte de maioria dos estudantes não indígenas, especialmente quando têm que conviver nesse espaço, até então não pensado para a presença indígena.

Nascimento (2014) escreve que a presença indígena nas instituições de ensino superior tem "provocado uma tensão no espaço acadêmico, no sentido de considerar o conhecimento a partir da diferença, de outras lógicas epistemológicas que não a produzida pela cultura ocidental e imposta como condiçáo única de compreensão e concepção de mundo" (NASCIMENTO, 2014, p. 35) e isso não tem sido diferente em nossas instituiçóes. A análise de Nascimento (2014) é observada nos depoimentos de acadêmicos em cursos de graduação quando mencionam:

A proximidade com as diferentes identidades causou recorrentes estranhamentos e proporcionou experiências transformadoras. Ter a oportunidade de poder dialogar diretamente com colegas indígenas, ouvir seus relatos e compartilhar de suas sabedorias e histórias fizeram com que em diversos momentos a história oficial já aprendida fosse questionada, levando a buscar uma nova história que considera os saberes dos povos tradicionais e que seja contada através desses povos.

A partir das aulas de História e Cultura Indígena pude conhecer muito mais os povos indígenas e rever todas as outras imagens que tinha sobre esse povo. O professor provocava e inquietava os acadêmicos Terena a falar sobre a sua cultura, a língua, a aldeia e a população. Apesar de no começo ter dificuldade de entender algumas delas, porque falavam baixo, fui aos poucos procurando ter mais atençáo e com isso consegui entender melhor alguns pontos da sua vida, de suas histórias, das dificuldades que sempre falaram e, também, compreender elementos dos seus cotidianos e das suas famílias. 
No início da graduação, tive a oportunidade de monitorar um aluno da etnia xavante em uma disciplina do curso de História. Foi uma experiência marcante em minha vida e um tanto desconfortável. $\mathrm{O}$ índio xavante falava pouquíssimo a Língua Portuguesa, embora tivesse uma grafia admirável. Hoje, quase no fim da graduação recordo essa experiência e concluo o quanto algumas disciplinas nos ajudaram a perceber outras histórias e o quanto somos diferentes enquanto seres humanos.

No começo da graduaçáo achava muito esquisito estudar com duas indígenas na sala. Pouco escutávamos suas vozes e as percebia por que chegavam sempre atrasadas. Com o passar do tempo, a turma foi se conhecendo melhor $\mathrm{e}$ as meninas começaram a se comunicar. Nas vezes que falavam em aula sempre falavam da sua comunidade e história. Conhecendo as meninas melhor pude compreender determinadas situações e hoje me revolto com aqueles que contam histórias erradas e falam sem entender sobre os povos indígenas (entrevista concedida aos autores em agosto/ setembro de 2018).

Os depoimentos mostram que a presença dos indígenas circulando e estudando nas universidades traz afetamento e envolvimento com os não indígenas, o que provoca o exercício de escuta. Inspirados nos escritos de Arantes (2012), o exercício de escutar o outro significa estar atento a todos os sentidos, imagens e línguas. É permitir se afetar pelas cores, cheiros e situaçóes. Escutar é silenciar, recolher e fazer do outro um protagonista do momento. Por isso que ao afetarem-se pela escuta do outro, nessse caso o indígena, os acadêmicos não indígenas criam possibilidades de reverem-se, conhecerem e estabelecerem outras relaçóes.

Nas relações que são estabelecidas e construídas, observamos que muitos acadêmicos não indígenas buscam conhecer melhor as histórias, desconstruir seus estereótipos de índios do passado e, ainda, realizam diálogos na intenção de favorecer inúmeras trocas, construções, traduções e intercâmbios culturais (CANDAU, 2016). Catherine Walsh (2009), em outras palavras, denomina esse processo de interculturalidade crítica, 
pois "permite considerar a construção de novos marcos epistemológicos que pluralizam, problematizam e desafiam a noção de um pensamento e conhecimento totalitários, únicos e universais" (WALSH, 2009, p. 25). A autora ainda escreve que a interculturalidade crítica procura:

o desenvolvimento e criação de compreensôes e condições que não só articulam e fazem dialogar com as diferenças num marco de legitimidade, dignidade, igualdade, equidade e respeito, mas que - ao mesmo tempo - alentam a criação de modo outros — de pensar, ser, estar, aprender, ensinar, sonhar e viver (WALSH, 2009, p. 25).

Nos depoimentos dos acadêmicos de graduação, observarmos o quanto a identidade, a diferença e a cultura do outro perturba, incomoda e traz desconforto (BHABHA, 1998). O silêncio, a dificuldade de comunicação e o seu modo de ser desestabilizam, principalmente nas relaçóes do eu e o outro. Por outro lado, verificamos que essas relaçôes afetam e marcam diretamente o sujeito, a ponto de registrar em seus depoimentos.

A colonialidade é outro fator presente nos depoimentos dos acadêmicos, o fato de o estudante dizer que "achava muito esquisito estudar com duas indigenas na sala” já demonstra essa situação. Nossas experiências docentes mostram-nos que muitos dos acadêmicos não indígenas que chegam ao ensino superior ainda possuem uma imagem cristalizada, marginalizada, subalternizada e inferiorizada dos povos indígenas. Uma imagem em que o sujeito está posicionado em um espaço de exclusão, hierarquização e preconceito, ou seja, um lugar marcado pelo colonialismo e amparado pelas relaçóes de poder (QUIJANO, 2005).

"Achar esquisito estudar com duas indigenas" faz-nos refletir o quanto somos frutos, filhos dessa colonialidade, que está nos discursos, nas atitudes, nos posicionamentos, no imaginário do sujeito. Colonialidade que contribui para a construção de novas identidades, silencia inúmeros saberes e continua sendo reproduzida em muitos espaços universitários. 
A colonialidade se mantém viva nos manuais de aprendizagem, nos critérios para os trabalhos acadêmicos, na cultura, no senso comum, na autoimagem dos povos, nas aspiraçóes dos sujeitos, e em tantos outros aspectos de nossa experiência moderna. Enfim, respiramos a colonialidade na modernidade cotidianamente (MALDONADO-TORRES, 2007, p. 131).

Verificamos na frase do acadêmico a surpresa de estar estudando com indígenas, pois podemos perceber que ele náo esperava que os povos indígenas pudessem conquistar esse espaço construído e amparado pela modernidade, de dominação branca e criação europeia.

Além dos indígenas nos cursos de graduação, as duas universidades em discussão neste texto registram a presença de indígenas nos cursos de pós-graduação stricto sensu, em nível de mestrado, mais precisamente nos programas voltados à formação de professores. Assim como na graduação, os pesquisadores indígenas que ingressam nos mestrados acabam tensionando com suas falas, histórias e saberes que trazem consigo. Segundo Nascimento (2014, p. 34-35) são

questôes estas que fazem parte do nosso dia a dia e que norteiam/desnorteiam as nossas leituras de mundo, as nossas ressignificaçóes e reorientaçáo de nossa episteme, agora atravessadas por outras epistemes, trazidas por aqueles que foram silenciados, subalternizados e, sobretudo, indicam o lugar que ocupamos nessa relação tão tensa e, ao mesmo tempo, táo enriquecedora.

Amparado nos estudos de Nascimento (2014) e na vivência docente nesses dois espaços da universidade, também procuramos verificar nos cursos de pós-graduação as contribuiçôes dos pesquisadores indígenas.

Mais especificamente no Programa de Pós-Graduação em Educação - mestrado e doutorado —, na UCDB, a convivência com pesquisadores indígenas de diversas etnias tem provocado deslocamentos epistemológicos e decoloniais, não só no âmbito da linha de pesquisa Diversidade Cultural e Educaçáo Indígena, em que se concentram, mas no 
contexto de todo o programa. Isso é possível ser observado no interesse de outras linhas que têm como eixo os temas: Políticas Públicas; História da Educação; Formação e Práticas Docentes. Há também o desenvolvimento de projetos de pesquisa que incluem a educação indígena, tais como a sua relação com os sistemas de ensino, com as questóes étnicas indígenas em escolas não indígenas, o uso das novas tecnologias em escolas indígenas 5 e outros.

Em artigo publicado por três professores pesquisadores desse programa (PAVAN; LOPES; BAKES, 2014) que têm convivência com pesquisadores indígenas ${ }^{6}$, eles relacionam as aprendizagens que têm tido nessa relação e que também tem sido a dos autores deste artigo. Entre outras destacam: a necessidade de estar sempre vigilantes e rever nossas teorias e ressignificá-las; o reconhecimento de que vivemos na colonialidade e que precisamos colocá-la em questão, pois ainda atravessa nossas relaçóes com os povos que foram hierarquizados pelo colonialismo; a importância de se estar atento às reflexôes orientadas por uma interculturalidade crítica que permite questionar "as assimetrias de poder, saber e viver que foram construídas pelo colonialismo e pela colonialidade" (PAVAN; LOPES; BAKES, 2014, p. 167).

Para os colegas não indígenas do programa tal convivência tem sido enriquecedora não só em sua formação como profissionais da educação, mas também como cidadãos que vivem o embate diário com uma sociedade ainda marcada pela exclusão e a negação da diferença. No Mato Grosso do Sul as lutas pela demarcaçáo de seus territórios e o cumprimento de seus direitos têm produzido um imaginário coletivo que só reforça os estereótipos históricos sobre os povos indígenas.

Nesse sentido, quando os indígenas produzem pesquisas usando a autobiografia, a autoetnografia, com base nas memórias daqueles que viveram os fatos, na descrição de suas pedagogias (processos próprios de aprendizagens, a relaçáo com o sagrado e a oralidade na produção do conhecimento, a compreensão do sujeito — criança —, outros modos de fazer pesquisa), quando temos a presença dos sábios e rezadores/xamãs nas aulas, nos grupos de pesquisa, em eventos como expositores, nas bancas como convidados especiais e pareceristas, quando envolvemos não indígenas em nossas militâncias acadêmicas (não só projetos de extensão, mas participação em encontros de suas associaçóes/movimentos, em re- 
uniōes nas comunidades) é possível perceber o desconforto com relação aos conhecimentos canônicos que seus colegas não indígenas têm como absolutos e também as fissuras que o contato provoca abrindo espaço para uma reinterpretação de conhecimentos e possibilidades de ressignificá-los. Como veremos em alguns depoimentos, essa decomposição de saberes está implícita e os farão/fazem mais próximos dos objetivos da Lei $\mathrm{n}^{\circ} \mathrm{o} 11.645 / 08$ :

Estudar, pesquisar e perceber o outro tendo ela (e) o indígena inserido no contexto nos faz refletir de forma mais humana o quanto é importante perceber o outro. É sentir a energia do nosso semelhante e nos colocar no lugar que também é nosso, a condição de humanidade, inserido no espaço e no tempo. O que deveria ser natural e passar a ter obrigatoriedade nos torna frágeis e fortes ao mesmo tempo.

Durante as aulas e outras atividades promovidas pelo Programa as leituras e os debates com a participação dos indígenas apontavam para perspectivas outras de compreensáo das teorias e dos modos como os indígenas interpretam as literaturas pelo filtro de suas epistemologias. Destaco ainda que, através da participação dos indígenas nos cursos de pós-graduação (neste caso, a PPGE-UCDB), suas produçôes começam a circular também como referências bibliográficas produzindo o que Walsh (2016) define como fissuras decoloniais provocando deslocamentos políticos e epistemológicos em espaços marcadamente eurocentrado, como a universidade. Essas fissuras podem ser observadas nas escritas de nossos textos que agora são carregados de interrogaçóes, (in) certezas, na tentativa do diálogo intercultural.

A partir de 2017, como doutoranda do PPGE(UCDB), percebo como agregador, provocador e pertinente todas as atividades que envolvam temáticas com foco intercultural e, sobretudo, indígena. Apesar dos meus estudos contemplarem outras perspectivas teóricas e sujeitos, ressalto que os Colóquios específicos sobre os 
povos indígenas realizados pelo referido Programa de Pós-Graduação, o Seminário Povos Indígenas e Sustentabilidade e as discussóes epistemológicas, teóricas e as ilustraçóes empíricas com enfoque indígena apresentados nas disciplinas obrigatórias do programa, como Educação Brasileira Contemporânea e Seminários de Tese 1 e 2, têm enriquecido meu limitado repertório sobre o tema com foco intercultural e, especificamente, indígena. Como educadora em uma instituição envolvida com o atendimento da demanda das comunidades indígenas - mesmo eu não sendo diretamente ligada ao DEINTER/UNIR - e, buscando o doutorado em Educação, entendo que a apreensão do tema no Programa de Pós-Graduação contribui, sim, para minha formação, pois provoca minha percepção sobre o outro e são estímulos para que eu possa conhecer e discutir sobre um universo que, direta ou indiretamente, faço parte e que tenho que me apropriar por respeito à diversidade, à democracia e ao compromisso com a educação.

No mestrado PPGE/UCDB, assim como na graduaçáo pela mesma instituição pude ter um contato próximo e de certa forma intenso com os indígenas. Isso na perspectiva de ouvir e sentir suas diferenças, isso por náo somente estarem, mas, por sua participação, por terem vez e voz dentro das disciplinas. Ouvir como, por exemplo, suas interpretaçôes textuais a partir de suas visōes de mundo, uma interpretação que diferia sempre da que eu havia feito, isso porque suas leituras iam além da teoria, mergulhavam e me levavam ao concreto, como se me desenhassem a teoria, como se dessem corpo a algo táo impalpável, inimaginável, como, por exemplo, ser indígena num contexto urbano e ser indígena em seu território, significado da terra, o significado de ser indígena, o significado de cultura, os impactos de um currículo monocultural para eles, o impacto da globalização para eles e para as novas geraçóes, compreensão de uma educação indígena, entre tantas outras discussóes como hibridismo, os efeitos profundos de uma histórica formação hegemônica que os invisibiliza, os exclui, os estereotipa e os priva de direitos. Ouvi a versão indígena da História, pois, a versão não-indígena era o que eu conhecia. Ouvir e 
sentir o quanto historicamente sofrem na luta por diretos, autoria, protagonismo, respeito sociocultural e na resistência por continuarem a existir. $\mathrm{O}$ ouvir e sentir para mim foi fundamental para a desconstrução dos preconceitos e estereótipos plantados no meu processo formativo de perspectiva hegemônica, monocultural e porque não dizer também, racista. As disciplinas cursadas no PPGE/UCDB proporcionavam e proporcionam debates e momentos de ouvir e sentir, de afetar e deixar- se afetar. Proporciona ouvir o "outro", aprender com o "outro" e por vezes nos coloca no lugar do "outro". Proporciona trocas de saberes e uma tomada de consciência do quáo pouco conhecemos do "outro" e falando em indígenas a História e Cultura Indígena se mostra de forma ampla e complexa, portanto, Histórias e Culturas Indígenas ante a gama das especificidades étnicas e culturais e que, no programa podemos nos dar conta no encontro com os "outros" Guarani Nandeva, Guarani/Kaiowá, Terena, Kadiwéu, Xavante, entre outras etnias presentes (entrevista concedida aos autores em agosto/setembro de 2018).

Teríamos muitos outros depoimentos para apresentar aqui, mas esses são potentes para representar as manifestaçóes e as afetaçóes que as circulaçóes de acadêmicos indígenas produzem em seus colegas não indígenas.

Embora nós, os autores, já tenhamos muitos anos de convivência política e acadêmica com as comunidades indígenas e do nosso posicionamento também político e teórico em nossas ações de pesquisadores e docentes, a presença dos indígenas na universidade tem evidenciado que a desconstrução do conhecimento hegemônico, monocultural colonizador, hierarquizado e naturalizado como verdadeiro e único, traz consequências territoriais, raciais, culturais e epistêmicas.

Partindo de nossas vivências, isso dá-se de forma muito mais forte, no momento do estranhamento e depois pela descoberta de que o dito conhecimento universal também é composto de saberes e culturas outras que foram inferiorizadas e que essa relação intercultural crítica (WALSH, 2009; 2016) pode provocar transformaçóes de cunho político, epistêmico, social, ético e, consequentemente, pedagógico. 
Parece ser esta a fundante questão posta pela Lei $n^{\circ}$ o $11.645 / 08$. Produzir pensamentos e atitudes outras que náo desenvolvam apenas o respeito ao outro, à diferença, mas que possam colocar em crise a nossa colonialidade, as nossas metanarrativas produzidas pela modernidade e ter aprendizagens outras, com os sujeitos outros, que trazem outras narrativas. Isso só será possível se intensificarmos os nossos diálogos com os indígenas e suas culturas e histórias, mote central da lei.

\section{REFERÊNCIAS}

ARANTES, E.M. de M. Escutar. In: FONSECA, T. et al.

(orgs). Pesquisar na diferença: um abecedário. Porto Alegre: Sulina, 2012. p. 93-96.

AZIBEIRO, N.E.; FLEURI, R.M. Paradigmas interculturais emergentes na educação popular. In: GARCIA, R.L. (org.). Diálogos Cotidianos. Petrópolis: DP/Faperj, 2010. p. 275-296.

BHABHA, H.K. O local da cultura. Belo Horizonte: Editora da UFMG, 1998.

BRASIL. Lei 10.639/2003, de 9 de janeiro de 2003. Altera a Lei no 9. 394, de 20 de dezembro de 1996. Diário Oficial da Uniāo, Poder Executivo, Brasília.

BRASIL. Lei no 11.645. Altera a Lei no 9.394, de 20 de dezembro de 1996, modificada pela Lei $n^{\circ} 10.639$, de 9 de janeiro de 2003, que estabelece as diretrizes e bases da educação nacional, para incluir no currículo oficial da rede de ensino a obrigatoriedade da temática "História e Cultura AfroBrasileira e Indígena". Diário Oficial da República Federativa do Brasil, Brasília, 2008.

CANDAU, V. M. "Ideias-força" do pensamento de Boaventura Sousa Santos e a educaçáo intercultural. In: ___ (org.). Interculturalizar, descolonizar, democratizar: uma educação "outra"? Rio de Janeiro: 7Letras, 2016.

IBGE. Censo 2010: população indígena é de 896,9 mil, tem 305 etnias e fala 274 idiomas. IBGE, 2010. Disponível em: $\leq$ https://censo2010.ibge.gov.br/noticias-ce nso?busca $=1 \& i d=3 \&$ idnoticia $=2194 \& \mathrm{t}=$ censo -2010 - poblacao-indigena-896-9mil-tem-305-etnias-fala-274\&view=noticia $>$. Acesso em: 20 jan. 2018.

LARROSA, B. J. Notas sobre a experiência e o saber de experiência. Revista Brasileira de Educação, Rio de Janeiro, n. 19, p. 20-28, 2002. http://dx.doi. org/10.1590/S1413-24782002000100003 
MALDONADO-TORRES, N. Sobre la colonialidad del ser: contribuciones al desarrollo de un concepto. In: CASTRO-GOMEZ, S.; GROSFOGUEL, R. (org.). El giro decolonial. Reflexiones para una diversidad epistémica más allá del capitalismo global. Bogotá: Siglo del Hombre Editores/Universidad Central/Instituto de Estudios Sociales Contemporáneos/Pontificia Universidad Javeriana/Instituto Pensar, 2007. p. 127-168.

MIGNOLO, W. D. El pensamiento decolonial: desprendimento y apertura. Un manifiesto. In: CASTRO-GOMEZ, S.; GROSFOGUEL, R. (org.). El giro decolonial: reflexiones para una diversidad epistémica más allá del capitalismo global. Bogotá: Siglo del Hombre Editores/Universidad Central/Instituto de Estudios Sociales Contemporáneos/Pontificia Universidad Javeriana/Instituto Pensar, 2007. p. 25-46.

NASCIMENTO, A. C. Fronteiras étnico-culturais e fronteiras da exclusão e o diálogo com as culturas ancestrais: uma construção difícil, mas possível. Revista Série-Estudos, Campo Grande, n. 37, p. 33-46, 2014.

PAVAN, R.; LOPES, M.C.P.; BACKES, J.L. A construção de um diálogo intercultural com indígenas por meio da pesquisa-ação não convencional. Acta Scientiarum, Maringá, v. 36, n. 1, p. 163-173, 2014. https://doi. org/10.4025/actascieduc.v36i1.21295

QUIJANO, A. Colonialidade do poder, eurocentrismo e América Latina. In: LANDER, E. (org.). A colonialidade do saber: eurocentrismo e ciências sociais: perspectivas latino-americanas. Buenos Aires: CLACSO, 2005.

RUSSO, K.; PALADINO, M. A Lei 11.645 e a visão dos professores do Rio de Janeiro sobre a temática indígena na escola. Revista Brasileira de Educação, Rio de Janeiro, v. 21, n. 67, p. 897-921, 2016. http://dx.doi.org/10.1590/ S1413-24782016216746

SACAVINO, S.B. Educação descolonizadora e interculturalidade: notas para educadora e educadores. In: CANDAU, V.M. (org.). Interculturalizar, descolonizar, democratizar: uma educação "outra"? Rio de Janeiro: 7 Letras, 2016. p. 188-202.

SKLIAR, C. Pedagogia (improvável) da diferença: se o outro não estivesse aí? Rio de Janeiro: D\&A, 2003.

WALSH, C. Interculturalidade, crítica e pedagogia decolonial: in-surgir, reexistir e re- viver. In: CANDAU, V.M. (org.). Educação intercultural na América Latina: entre concepçóes, tensóes e propostas. Rio de Janeiro: 7 Letras, 2009. p. 12-42.

WALSH, C. Notas pedagógicas a partir das brechas decoloniais. In: CANDAU, V.M. (org.). Interculturalizar, descolonizar, democratizar: uma educação "outra"? Rio de Janeiro: 7 Letras, 2016. p. 64-75. 


\section{NOTAS}

1. Permanência de indígenas no ensino superior é um programa financiado pela Fundação Ford que está vigente desde o fim de 2005. Antes era um dos subprojetos do Trilhas de Conhecimento, coordenado pelo LACED/UFRJ, mas atualmente reúne uma parceria de quatro universidades: Universidade Católica Dom Bosco (UCDB); Universidade Estadual de Mato Grosso do Sul (UEMS); Universidade Federal da Grande Dourados (UFGD) e Universidade Federal de Mato Grosso do Sul (UFMS).

2. Projeto financiado pela Fundação Ford e executado em parceria entre a Universidade Estadual de Mato Grosso do Sul e a Universidade Católica Dom Bosco. Encerrou-se no ano de 2015.

3. NEPPI, criado em 1995, concentra o Centro de Documentação Antônio Brand (CEDOC), a Revista TELLUS, o Rede de Saberes, equipe de pesquisadores (alunos e docentes), extensionistas e assessores.

4. Seminário Povos indígenas e Sustentabilidade, realizado pelo Programa de Pós-Graduação a cada dois anos e anualmente o Encontro de Estudantes Indígenas.

5. Entre outras atividades, destacam-se: a implementação da Lei no $11.645 / 08$ no ensino fundamental (Mestrado/Linha 2); o trabalho de professores não indígenas de matemática no contexto da escola indígena: olhares para (im)possibilidades de bemestar/mal-estar docente (Doutorado/Linha 2); formaçáo continuada de professores indígenas e não indígenas: implicaçóes e possibilidades interculturais em contexto presencial e em redes sociais (Doutorado/Linha 2), entre outros.

6. Justino Sarmento Rezende (Tuyuca), Eliane Gonçalves de Lima (Terena), Antônio Carlos Seizer da Silva (Terena), Maria de Lourdes Elias Sobrinho (Terena), Celinho Belizário Lima (Terena), Celma Francelino Fialho (Terena), Elda Vasques Aquino (Kaiowá), Teodora de Souza (Guarani Nhandeva), Eliel Benites (Kaiowá), Edineide Bernardo Farias (Terena), Claudemiro Pereira Lescano (Kaiowá), Lidio Cavanha Ramires (Kaiowá), Gerson Pinto Alves (Terena), Evelin Tatiane da Silva Pereira (Terena), Aquilino Tsere'ubu'o Tisirui'a (Xavante), Katiana Barbosa de Carvalho (Kaiowá), Eliezer Martins Rodrigues (Guarani), Gaudêncio Campos ( Dessano); Jabez Gabriel ( Terena); Valdenir Souza( Guarani Nhandeva).

Recebido em 6 de fevereiro de 2019.

Aprovado em 9 setembro de 2019. 